\title{
APLIKASI MULTIMEDIA INTERAKTIF PENGENALAN NEGARA ASEAN UNTUK SISWA KELAS VI SD
}

\author{
Budi Sudrajat, S.Kom., M.Kom \\ E-mail : budi.bst@bsi.ac.id
}

\begin{abstract}
ABSTRAK
Aplikasi pengenalan Negara ASEAN ditujukan untuk siswa-siswi sekolah dasar dalam mempelajari dan mengenal Negara Anggota ASEAN, dimana siswa-siswi dapat lebih mudah mempelajarinya dibanding dengan hanya membacanya melalui buku saja yang kadang isinyapun kurang menarik dan juga untuk menambah pengetahuan mereka. Dengan membuat suatu aplikasi pembelajaran mengenai Negara ASEAN dengan Adobe Flash, diharapkan dapat mengatasi masalah tersebut karena tampilannya menggunakan efek animasi yang membuat tampilanya tidak bersifat monoton dan dapat menarik perhatian penggunanya. Negara Anggota ASEAN yang akan ditampilkan di Aplikasi ini adalah Negara Indonesia, Malaysia, Singapura, Brunei Darussalam, Filipina, Thailand, Kamboja, Laos, Myanmar, dan Vietnam. Informasi yang ada dalam aplikasi ini adalah hanya sejarah singkat dari masing-masing Negara, lambang Negara, informasi negara, sejarah, Bendera Negara, sejarah mengenai ASEAN, dan terdapat kuis yang berisi tentang ASEAN.
\end{abstract}

Kata Kunci : ASEAN, Animasi, Aplikasi Pembelajaran

\begin{abstract}
The software which now has gained a large enough number of users and is able to create animations which are very appealing to the general public, especially the students of the primary school. ASEAN Countries recognition applications intended for elementary school students in studying and knowing the ASEAN Member States, where the students can more easily learn than just reading through the book just that sometimes it even less attractive and also to increase their knowledge. By creating a learning application on ASEAN countries with Adobe Flash, is expected to solve the problem because the display uses animation effects that make ya look not monotonous and can attract the attention of users. Member States that will be displayed in this application is the State of Indonesia, Malaysia, Singapore, Brunei Darussalam, the Philippines, Thailand, Cambodia, Laos, Myanmar, and Vietnam. The information contained in this application is just a brief history of each country, the symbol of the State, state information, history, flag state, the history of ASEAN, and there is a quiz that contains about ASEAN.
\end{abstract}

Keywords $\quad$ :ASEAN, Animation, learning applications 


\section{PENDAHULUAN}

Ilmu pengetahuan merupakan kebutuhan dasar setiap manusia yang pada dasarnya harus dipenuhi sebagai bekal hidup dimasa mendatang. Sebagai manusia yang dibekali akal dan pikiran menjadikan manusia mempunyai rasa keingintahuan yang besar terhadap pendidikan dalam metode pembelajaran untuk mendapatkan pengetahuan yang lebih luas.

Seiring dengan kebutuhan akan metode pembelajaran yang lebih efektif dan efisien, pemanfaatan teknologi informasi dan komunikasi untuk pendidikan sangat diperlukan. Konsep pembelajaran ini membawa pengaruh terjadinya proses transformasi pendidikan konvensional ke dalam bentuk digital, baik secara isi dan sistemnya. Dengan pengembangan konten oleh guru maka proses belajar mengajar lebih efektif dan efisien sesuai dengan Kurikulum Tingkat Satuan Pendidikan.

Pembelajaran dari tahun ke tahun semakin baik dan beragam melihat ke butuhan dan saran yang ingin dicapai dari para siswa ataupun dari orang yang ingin belajar. Buku pelajaran mengenai Ilmu Pengetahuan Sosial yang beredar di pasaran khususnya yang membahas mengenai ASEAN bentuk penyajiannya kurang menarik karena bersifat monoton yang hanya menampilkan gambar dan tulisan saja. Maka penulis mencoba membuat aplikasi baru berupa Media Pembelajaran Interaktif,diharapkan dapat mengatasi masalah tersebut karena tampilannya menggunakan efek animasi yang membuat tampilannya tidak bersifat monoton dan dapat menarik perhatian penggunanya. Dengan adanya program aplikasi ini diharapkan mampu menambah motivasi belajar peserta didik dan mengubah system pembelajaran yang ada sekarang menjadi system pembelajaran yang lebih efektif dan berbasis teknologi.

\section{TINJAUAN PUSTAKA}

Salah satu contoh media pembelajaran berbasis multimedia yang nantinya digunakan dalam penelitian ini adalah media pembelajaran model tutorial. Media ini menggabungkan dan mensinergikan semua media yang terdiri dari teks, grafis, foto, video, animasi, musik, narasi, dan interaktivitas yang diprogram berdasarkan teori pembelajaran. Menurut Munadi (2008), Keuntungan menggunakan bahan ajar multimedia dibandingkan dengan media lain adalah "meningkatkan motivasi belajar, memungkinkan siswa untuk belajar mandiri,interaktif, meningkatkan tingkat ingatan, serta lebih efesien dan efektif".

Menurut Suheri (2006), "Belajar adalah merupakan yang tidak akan pernah berhenti dari detik demi detik sejak manusia lahir sampai mati. Manusia sejak lahir belajar untuk mengenal dirinya dan juga lingkungannya. Manusia berbeda dengan Makhluk ciptaan Tuhan lainnya karena dia memiliki akal pikiran. Akal pikiran inilah yang menyebabkan manusia secara alami serta reflek berusaha untuk belajar tentang apa saja. Manusia melakukan pembelajaran dengan menggunakan berbagai cara, namun tujuannya sama yaitu memahami apa yang dipelajari. Berbagai cara belajar telah dilakukan manusia diantaranya dengan mendengarkan, mengamati lingkungan, konsultasi dan lain sebagainya".

Menurut Hariyanto (2013), Perancangan dan implementasi pembelajaran secara jelas, bermakna dan bila perlu memanfaatkan media yang menjembatani proses perolehan materi pelajaran menjadi mudah dan mengalir sesuai dengan mental siswa. Untuk itu perlu adanya media pembelajaran yang relevan dan sesuai untuk membangkitkan dan memelihara motivasi belajar siswa, sehingga siswa tidak lagi pasif selama proses pembelajaran.

Menurut Suraji (2013), Media pembelajaran selalu terdiri dari atau perangkat keras (hardware) dan unsur pesan yang dibawanya (message/software). Perangkat lunak (software) adalah informasi atau bahan ajar itu sendiri yang akan disampaikan kepada siswa, sedangkan perangkat keras adalah sarana atau peralatan yang akan digunakan untuk menyajikan pesan/bahan ajar tersebut. Lanjutnya fungsi utama media pembelajaran yaitu sebagai sarana bantu untuk mewujudkan situasi pembelajaran yang lebih efektif. Fungsi lain yaitu untuk mempercepat proses belajar 
sehingga diharapkan dapat meningkatkan kualitas proses pembelajaran dan mengurangi verbalisme.

\section{METODE PENELITIAN}

Subjek penelitian yang akan dibahas adalah Aplikasi Multimedia Interaktif pengenalan Negara ASEAN untuk siswa Kelas VI SDN. Dengan melakukan wawancara kepada guru dan siswa kelas VI dan melakukan pengamatan kepada siswa untuk pelajaran Ilmu Pengetahuan Sosial khususnya tentang ASEAN dantentang materi mereka seluruhnya maka akan dirancang untuk pembuatan animasi interaktif yang terdapat di dalamnya tentang soal-soal, peta ASEAN, Negara-negara di ASEAN, berdirinya ASEAN, pengenalan ASEAN, dan pengenalan Negara ASEAN. Dengan pembuatan animasi interaktif guru lebih mudah menyampaikan atau mejelaskan tentang penjelasan materi dari materi yang telah ada dalam aplikasi ini dengan gambar dan animasi yang menarik.

Langkah penelitian pertama kali adalah pengumpulan data-data yang di butuhkan, baik dari sekolah khususnya kelas VI tentang materi pembelajaran Ilmu Pengetahuan Sosial khususnya ASEAN serta wawancara dengan guru kelas VI. Kemudian melakukan perancangan dan implementasi bahan yang terkumpul mengenai materi-materi pembelajaran Ilmu Pengetahuan Sosial khususnya ASEAN untuk kelas VI yang berbasis animasi interaktif.

\section{HASIL DAN PEMBAHASAN}

\section{User Requirement}

Komputer adalah suatu sarana multifungsi yang salah satunya dapat digunakan untuk melatih kecerdasan, lebih mudah di mengerti dan memberikan daya tarik pelajaran ini. Maka dari itu diperlukan adanya suatu sistem yang menggunakan teknologi digital ini agar pengguna dapat menggunakan salah satu fungsional dari komputer itu sendiri yang telah disebutkan di atas sehingga terbentuklah suatu metode perangkat lunak interaktif yang dapat dimanfaatkan bagi sekolah khususnya siswasiswi kelas VI. Selain untuk pembelajaran dan melatih kecerdasan, tentu saja dapat digunakan sebagai media hiburan dan merangsang saraf motorik anak.

Perangkat lunak ini dibuat atas dasar pelatihan, observasi, studi pustaka dan wawancara kepada tim pengajar kelas VI sekoah dasar untuk mematangkan apa yang didapatnya selama di sekolah dengan kemasan dalam bentuk aplikasi multimedia interaktif. Dengan harapan bahwa perangkat lunak ini dapat mendorong siswa-siswi lebih mengenal lembaga ASEAN, memperluas wawasan dan pengetahuan siswasiswi.

Diharapkan pula siswa-siswi akan menikmati perangkat lunak interaktif tersebut di rumah bersama orang tuanya yang tentunya akan menambah manfaat perangkat lunak tersebut selain sebagai sebuah media pembelajaran juga dapat menambah wawasan siswa-siswi juga sebagai sarana komunikasi yang baik dalam sistem parenting.

Identifikasi kebutuhan dari pemain dilakukan dengan tujuan yaitu :

a. Sistem yang dibuat telah difokuskan kepada kebutuhan siswa-siswi.

b. Memudahkan dalam pembuatan programnya.

c. Memudahkan pengembangan sistem selanjutnya

Aplikasi multimedia interaktif yang menjelaskan tentang ASEAN ini memiliki aturan yang sangat sederhana, di mana pemain disuguhkan tiga buah menu yang berkaitan dengan organisasi ASEAN. Dari menu-menu tersebut pemain bisa mendapatkan sejarah tentang ASEAN, identitas negara-negara sebagai anggota ASEAN, dan evaluasi yang menguji pengetahuan pemain mengenai ASEAN di mana pemain harus menjawab sepuluh buah pertanyaan dengan baik dan benar. Di bagian menu sejarah pemain dapat mengetahui sejarahsejarah ASEAN yang di dalamnya terpisah menjadi empat bagian. Kemudian pada menu tentang peta ASEAN pemain dapat memilih salah satu icon dari yang terdapat di dalam peta untuk mengetahui identitas negara-negara anggota ASEAN, dengan penjelasan, bendera, lambang negara, dan contoh keadaan alamnya. 
Menu kuis pemain akan diuji pengetahuannya dari apa yang didapatkannya seputar ASEAN. Bila jawaban benar, maka pemain akan mendapatkan tambahan poin sebanyak sepuluh dan jika salah maka poin berkurang sebanyak lima.

\section{State Transition Diagram}

Diagram ini digunakan untuk membantu analisis, perancang dan pengembang untuk memahami perilaku objek di sistem. State transition diagram mempresentasikan perilaku suatu sistem dengan menggambarkan keadaan-keadaannya (state) dan kejadian-kejadian yang dapat membuat sistem berubah keadaan.

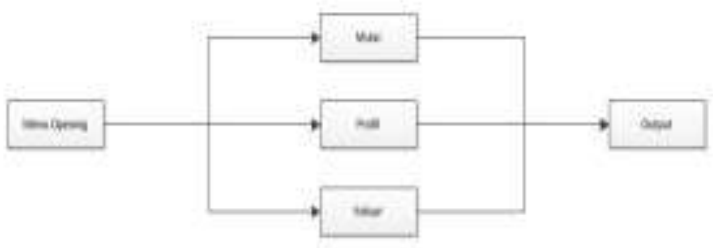

Gambar 1. State transition diagram

\section{Kopleksitas Siklomatis}

Kompleksitas siklomatis (pengukuran kuantitatif terhadap kompleksitas logis suatu program) dari grafik alur dapat diperoleh dengan perhitungan :

$$
\mathrm{V}(\mathrm{G})=\mathrm{E}-\mathrm{N}+2
$$

Dimana :

$\mathrm{E}=$ Jumlah edge grafik alir yang ditandakan dengan gambar panah

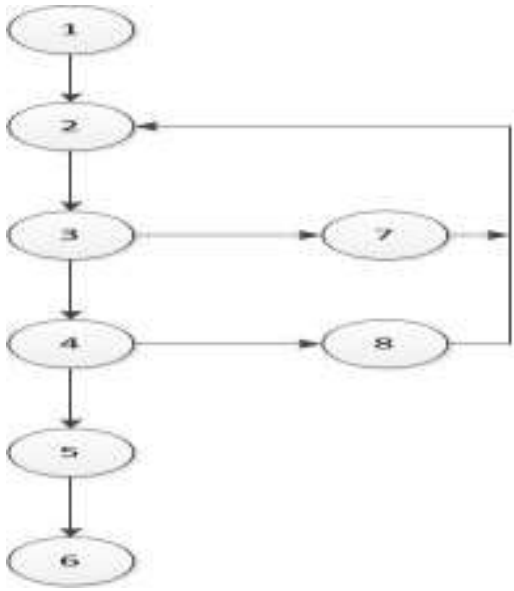

$\mathrm{N}=$ Jumlah simpul grafik alir yang ditandakan dengan gambar lingkaran

Sehingga kompleksitas siklomatisnya

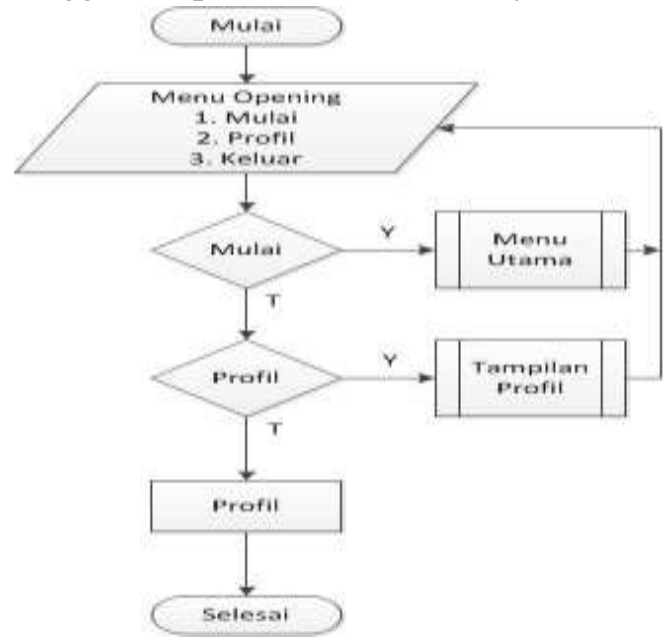

$\mathrm{V}(\mathrm{G})=9-8+2=3$

Basis set yang dihasilkan dari jalur independent secara linier, adalah jalur sebagai berikut :

$$
\begin{aligned}
& 1-2-3-4-5-6 \\
& 1-2-3-7-2 \\
& 1-2-3-4-8-2
\end{aligned}
$$

Ketika aplikasi dijalankan, maka terlihat bahwa salah satu basis set yang dihasilkan adalah $1-2-3-4-5-6$

\section{Perancangan Storyboard}

Storyboard Storyboard adalah sebuah penggambaran jalan cerita sesuai dengan isi cerita dan berisi tentang pengambilan sudut gambar, pengisian suara, serta efek-efek khusus. Penggambaran jalan cerita berbentuk potongan gambar atau komik yang disertai penjelasan alur cerita. Fungsi storyboard adalah menerjemahkan isi skenario secara visual atau penggambaran secara singkat.

Storyboard menjelaskan tentang susunan materi yang disampaikan pada detik demi detik beserta suara, grafis, animasi, dan video yang dibutuhkan. 
1. Tampilan Menu Opening

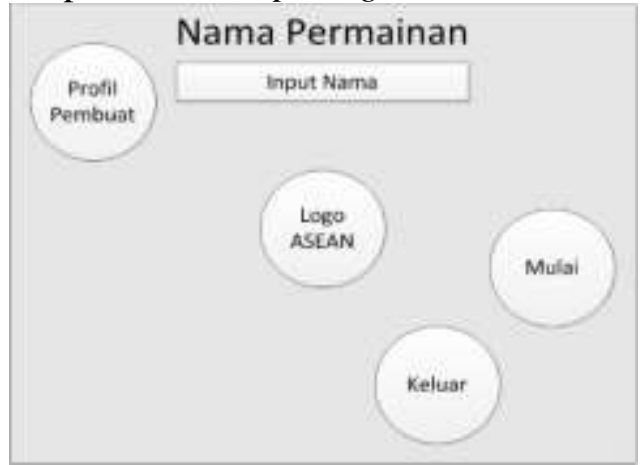

Gambar 2. Rancangan Menu Opening

Ketika permainan dibuka dan dijalankan akan muncul sebuah tampilan awal yang berisi tentang identitas pembuat permainan, tombol main, tombol keluar dan input nama.

\section{Tampilan Menu Utama}

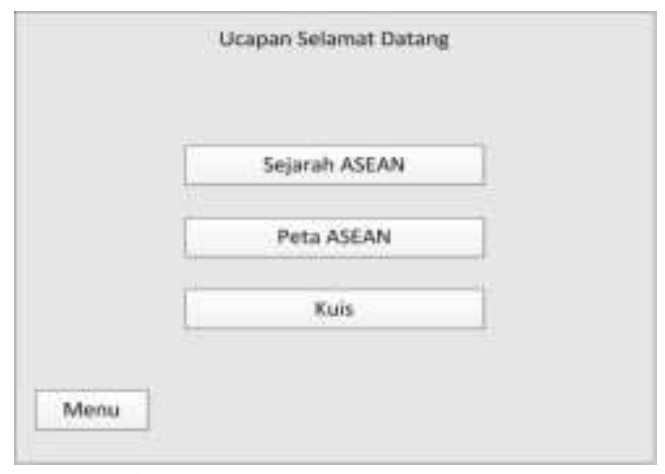

Gambar 3. Rancangan Menu Utama

Pemain dapat memilih menu yang disediakan untuk langsung mengetahui fitur-fitur yang ada pada perangkat lunak interaktif ini

\section{Tampilan Menu Sejarah}

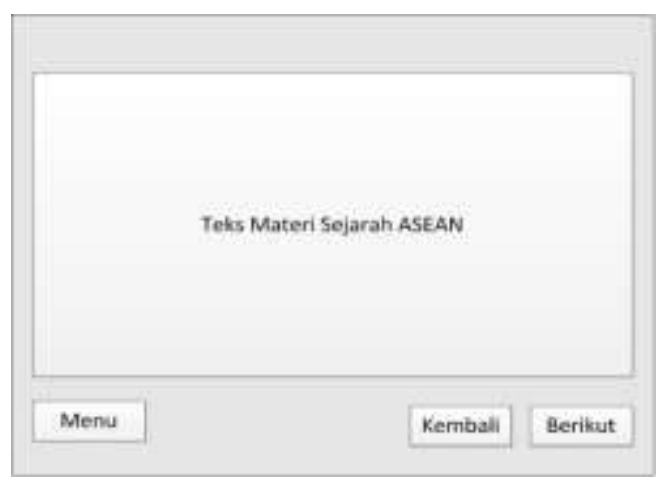

Gambar 4. Rancangan Menu Sejarah
Pada bagian ini terdapat teori ASEAN yang diuraikan, pemain juga dapat mengklik tombol Berikut/Kembali agar dapat menuju materi berikutnya atau sebelumnya.

\section{Tampilan Peta ASEAN}

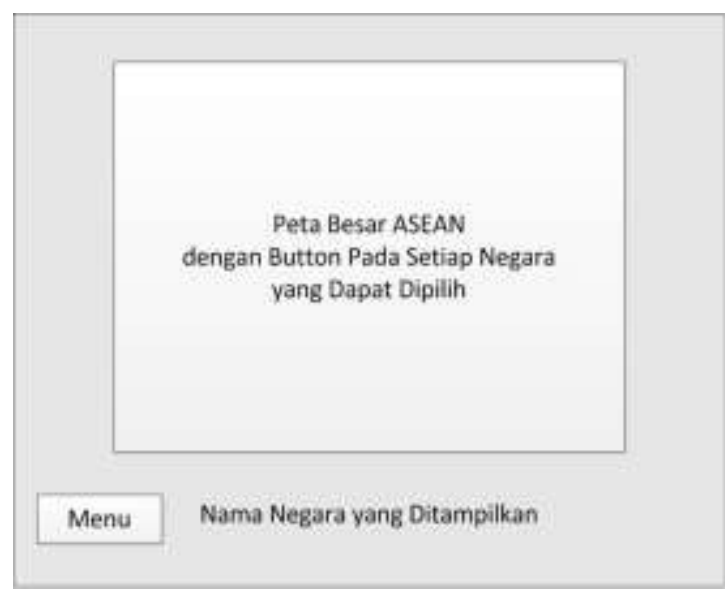

Gambar 5. Rancangan Peta ASEAN

Terdapat peta besar ASEAN dengan button pada setiap negara yang dapat dipilih. Juga akan tampil nama negara yang akan muncul ketika mouse over tiap button.

\section{Tampilan Indentitas Negara}

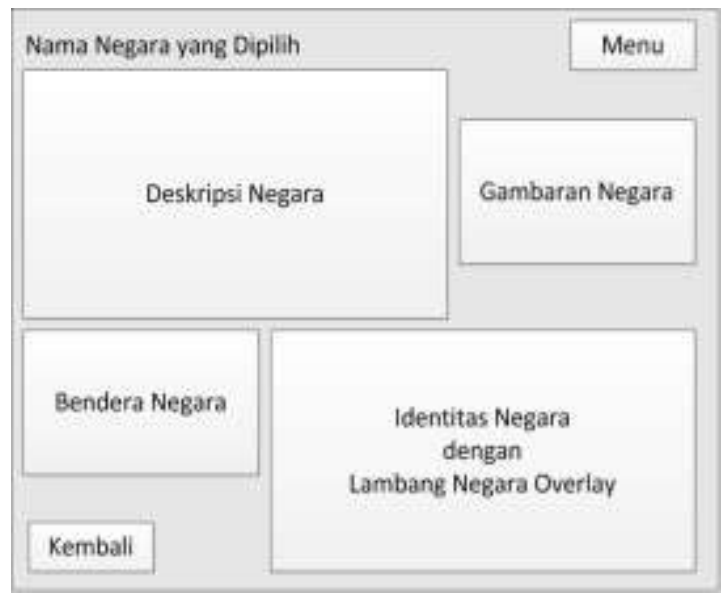

Gambar 6. Rancangan Identitas Negara

Di bagian ini pemain dapat melihat Identitas, deskripsi, bendera, lambang, gambaran dari negara dipilih. Kemudian disediakan navigasi agar pemain dapat kembali ke peta atau ke menu utama. 


\section{Tampilan Soal}

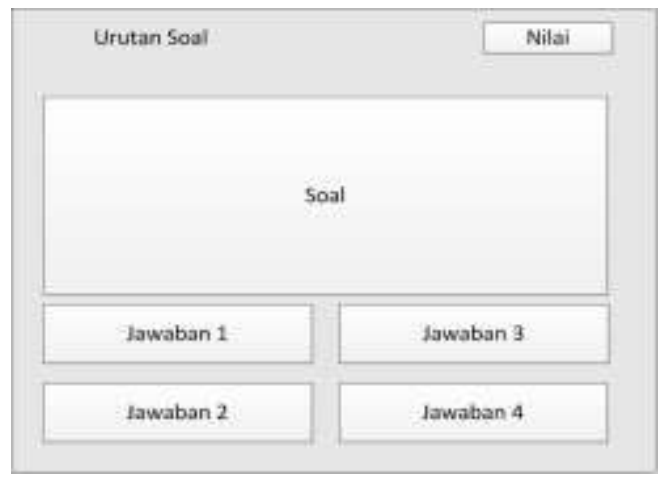

Gambar 7. Rancangan Soal

Disini nilai akan dikalkulasikan dan akan terlihat penjelasan prestasi yang dicapai sesuai dengan kriteria nilai.

\section{Hasil Program}

1. Tampilan halaman user interface menu opening

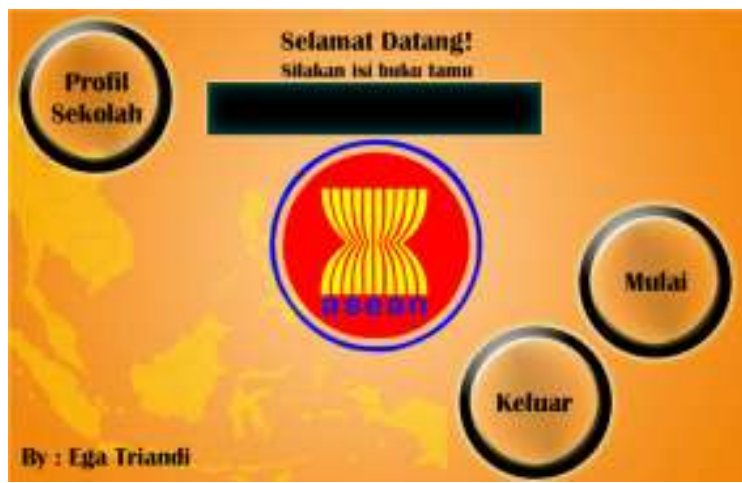

Gambar 8. Interface Menu Opening

2. Tampilan user interface menu utama

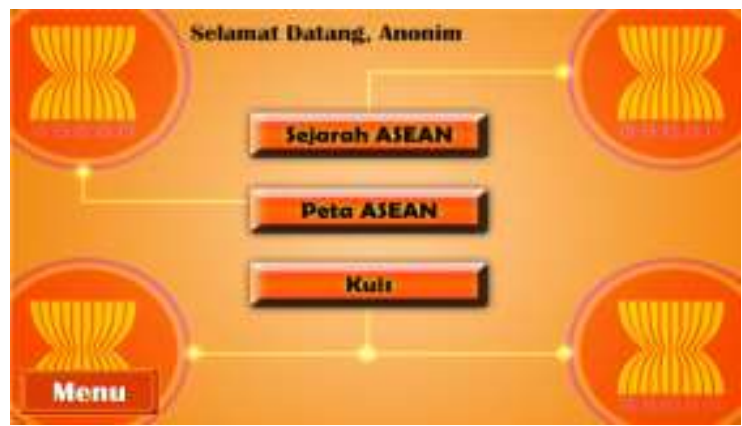

Gambar 9. Interface Menu Utama
3. Tampilan user interface menu sejarah ASEAN

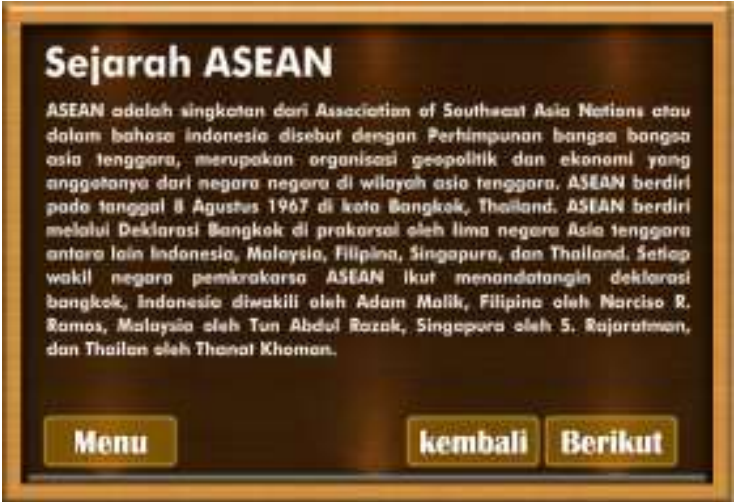

Gambar 10. Interface Sejarah ASEAN

4. Tampilan user interface peta ASEAN

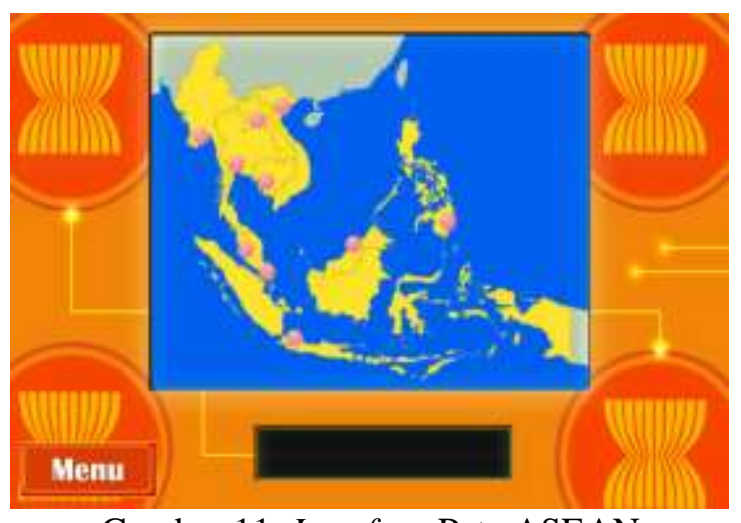

Gambar 11. Interface Peta ASEAN

5. Tampilan user interface deskripsi Negara pada menu peta ASEAN

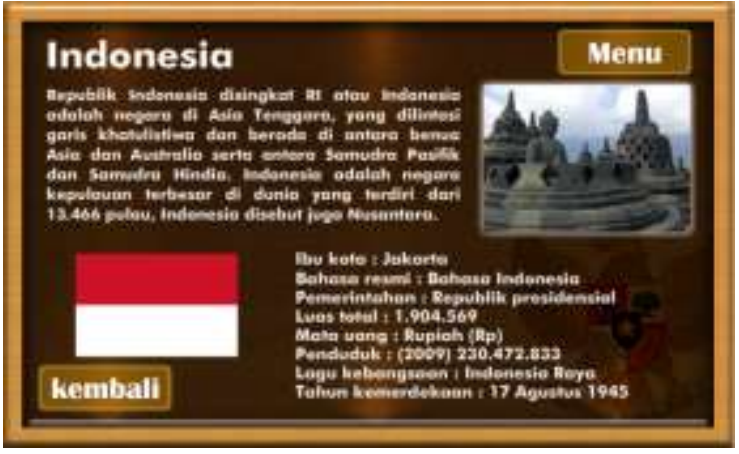

Gambar 12. Deskripsi Negara 
6. Tampilan user interface menu kuis

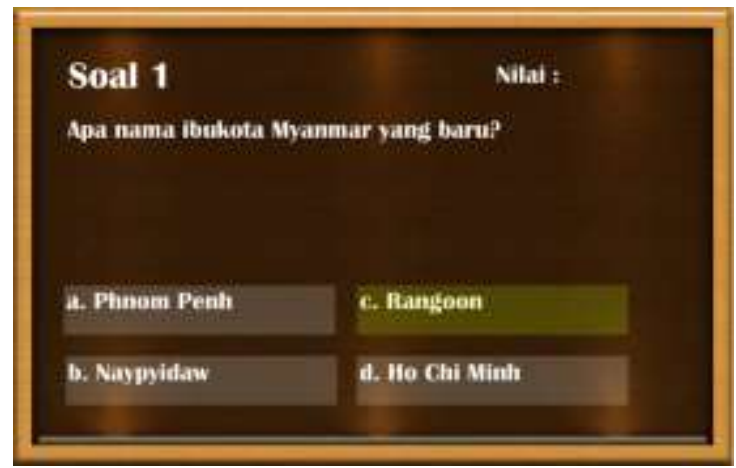

Gambar 13. Interface Kuis

6. Tampilan user interface nilai pada menu kuis

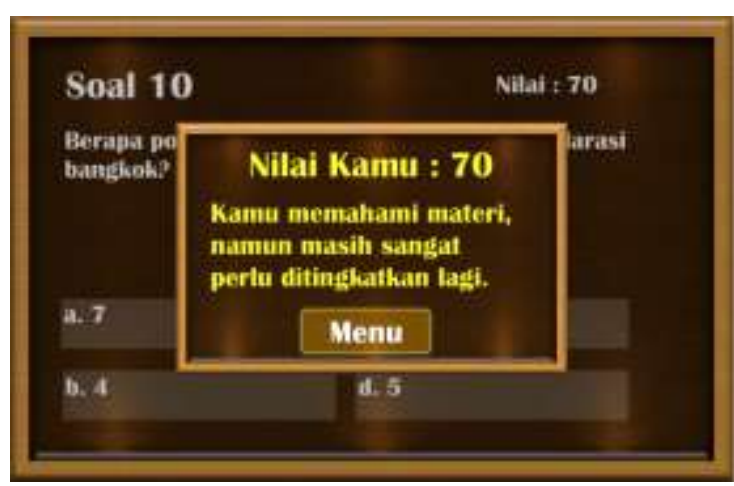

Gambar 14. Interface Nilai

KESIMPULAN DAN SARAN

\section{Kesimpulan}

Berdasarkan hasil penelitian dan pembahasan yang telah diuraikan peneliti maka di dapat ditarik kesimpulan sebagai berikut :

1. Telah dilakukan uji coba program yang menunjukan bahwa media pembelajaran yang telah dibuat dapat berjalan dengan baik.

2. Perangkat animasi multimedia Pembelajaran sebagai alternatif transformasi pengetahuan.

3. Dengan adanya perancangan aplikasi multimedia pembelajaran mengenai ASEAN dapat menjadi alternatif atau alat bantu guru kelas VI dalam pelaksanaan kegiatan belajar mengajar lebih menarik karena didukung adanya media pembelajaran.

4. Dengan adanya media pembelajaran yang menarik dan dapat memotivasi siswa dalam mempelajari sebuah mata pelajaran yang di sampaikan maka secara tidak langsung juga akan meningkatkan prestasi belajar para siswa.

5. Animasi Multimedia Pembelajaran sebagai media pembelajaran yang bisa didistribusikan dengan ongkos produksi yang relatif murah (harga sebuah CD lebih murah dibandingkan dengan sebuah buku dengan puluhan halaman) dan dapat membuka pintu perkenalan dengan dunia Animasi Multimedia pembelajaran yang bisa dikembangkan menuju corporate training, customer support serta bisnis tutorial training. media pembelajaran alternatif yang mudah, singkat, menyenangkan dan murah

\section{Saran}

Berdasarkan hasil kesimpulan tersebut, penulis mencoba memberikan saran-saran dan hal-hal yang masih perlu diperhatikan mengenai media pembelajaran interktif.

1. Dalam pembuatan media pembelajaran ini, peneliti mengalami keterbatasan waktu dan juga sarana pembuatan sehingga media pembelajaran yang di hasilkan masih banyak kekurangan dalam penyajian isi, tampilan dan audio. Maka nantinya dalam penyajian isi akan terus di perbaharui mengikuti kurikulum yang berlaku saat itu, dalam tampilan dan isi akan ditambahkan gambar atau animasi yang lebih menarik dari sebelumnya agar menambah minat siswa dan penggunanya.

2. Aplikasi ini akan semakin baik apabila dikembangkan lebih lanjut untuk mendapatkan hasil yang lebih baik dan maksimal dari sebelumnya dengan peningkatan fitur yang lebih baik di masa depannya, dan dapat di tambahkan menu permainan agar siswa tidak merasa jenuh agar program animasi ini jauh lebih baik dari segala sisi

3. Diharapkan media pembelajaran interaktif lebih dapat berperan dalam proses belajar mengajar di masa mendatang, sehingga suasana belajar mengajar lebih menyenangkan dan dapat memotivasi siswa dalam belajar.

4. Semoga siswa dan guru dapat memanfaatkan media pembelajaran interaktif yang 
dihasilkan oleh peneliti dan dapat digunakan secara baik.

\section{DAFTAR PUSTAKA}

Hariyanto Dwi Agung dan Pujiono

Wahyu.2013.Perancangan dan

Implementasi Pembelajaran Perkalian dan Pembagian Bilangan Untuk Sekolah Dasar Kelas 2.e-ISSN:2338-5197: Jurnal Sarjana Tehnik Informatika Volume 1 Nomor 1,juni 2013.

Munadi, Yudhi. 2008. Media Pembelajaran. Jakarta: Garuda Persada Press.

Suheri, Agus. 2006. Animasi Multimedia Pembelajaran. Vol 2 - No. 1 Periode Juli - Desember 2006.

Suraji, Gesang Kristianto. 2013.Perancangan Media Pembelajaran Ips Kelas 6 di Sekolah Dasar Negeri 2 Rowobungkul Kabupaten Blora Berbasis Multimedia Interaktif. Seminar Riset Unggulan Nasional Informatika dan Komputer Vol 2 No 1 - Maret 2013, ISSN 2302-1136. 